\title{
Hacer (otra) historia Construcción de una genealogía en la obra de Effy Beth ${ }^{1}$
}

\author{
Make (Other) History \\ Genealogy Building in the Work of Effy Beth
}

\begin{abstract}
Lázaro Olier
laru09@gmail.com

Instituto de Investigación en Producción y Enseñanza del Arte Argentino y Latinoamericano. Facultad de Bellas Artes. Universidad Nacional de La Plata. Argentina
\end{abstract}

Recibido: 3/10/2018 Aceptado: 9/1/2019

\begin{abstract}
Resumen
En el presente artículo se realizará un análisis de un corpus de obras de la artista trans Elizabeth Mía Chorubczyk (1988-2014), también conocida como "Effy Beth", considerando las relaciones que éstas articulan con la historia del arte y con las narrativas institucionalizadas de los feminismos. La obra de Effy constituye un complejo dispositivo de construcción y de acceso al pasado donde, a partir de la cita a artistas mujeres cis y feministas, principalmente europeas y estadounidenses, y de la estrategia poético-crítica de retomar temas y procedimientos artísticos trabajados por las mismas, se tensionan los límites de dichas narrativas para señalar las mecánicas de poder cisnormado que operan en los relatos de la historia del arte.
\end{abstract}

\section{Palabras clave}

Genealogía; queer; feminismos; cisnorma; Effy

\begin{abstract}
In this paper we'll analize a body of works by trans artistElizabeth Mía Chorubczyk (1988-2014), also known as "Effy Beth», considering the relationships they articulate with art history and with institucionalized narratives of feminisms. Effy's work constitutes a complex device of construction and accesss to the past where,starting from references to feminist cis women artists, mainly american and european, and the poetic-critical strategy of retaking themes and artistic procedures worked by them, the limits of these narratives are stressed, pointing out cisnormative power mechanics that operate regulating and administrating the art history narrations.
\end{abstract}

\section{Keywords}

Genealogy; Queer; Feminisms; Cisnorm; Effy

\footnotetext{
1 Este artículo se realizó con el apoyo de las Becas a las Vocaciones Científicas de Consejo Interuniversitario Nacional, e marco del proyecto de investigación "Genealogías críticas de las desobediencias sexuales desde el sur", del Instituto de del Arte Latinoamericano (IPEAL), de la Facultad de Bellas Artes (FBA), de la Universidad Nacional de La Plata (UNLP).
} 
2 Breve descripción personal que aparece en uno de sus blogs.
Elizabeth Mía Chorubczyk (1988-2014) fue conocida por su apodo "Effy Beth" y también por los nombres artísticos con los que designó sus blogs: Effýmia o Effýmine. Se definió como mujer trans, artista conceptual, performática y feminista queer. ${ }^{2}$ Nacida en Israel, vivió en la Argentina desde los cinco años. En 2010 ingresó a la carrera de Artes Visuales de la Universidad Nacional de las Artes (UNA) (en ese momento, Instituto Universitario Nacional de Arte). Su obra, realizada entre 2009 y 2014, es extensa e incluye la realización de numerosas performances en la ciudad de Buenos Aires como cuerpo de producción central dentro de su práctica artística.

En esta investigación proponemos abordar la obra de Effy como un complejo dispositivo de construcción y de ingreso diferencial al pasado, es decir, un conjunto de estrategias, prácticas y mecanismos que articulan elementos artísticos y discursivos ordenándolos en un sentido particular. El concepto de dispositivo, según la formulación que propone Jacques Aumont (1992), hace referencia a un conjunto de «medios y técnicas de producción de las imágenes, su modo de circulación y, eventualmente, de reproducción, los lugares en los que ellas son accesibles, los soportes que sirven para difundirlas» (p. 143). Así mismo, el dispositivo «regula la relación del espectador con sus imágenes en un cierto contexto simbólico» que es también, necesariamente, un contexto social (Aumont, 1992, p. 202).

Nos interesa analizar este dispositivo poniendo especial énfasis en las relaciones que diagrama con una genealogía artística particular. El concepto de genealogía artística es entendido aquí como una organización más o menos estable de artistas y de sus producciones a partir del cual se pretende dar cuenta de un flujo de la historia y, en cierta medida, explicar o dar sentido al presente, resaltando casos que comparten características; una especie de sintonía construida entre episodios que se encuentran separados en un tiempo y espacio determinado.

Realizaremos una serie de preguntas que apuntan a profundizar nuestro análisis sobre el vínculo entre la producción artística de Effy y la genealogía en la que se inscribe: ¿a partir de qué estrategias la artista ingresa y se enuncia como parte una genealogía? ¿Qué caracteriza dicha genealogía? ¿Qué efectos posibles traza Effy ingresando en esta genealogía? ¿Cuáles son las razones que hacen que ese ingreso sea queer? y ¿Qué nos permite y por qué leer sus producciones en relación con tal genealogía?

\section{Sobre las fuentes de la investigación}

Las obras de Effy son múltiples, fueron elaborados a partir de diversos procedimientos realizados de diferentes maneras: 
3 En este artículo reemplazaremos el plural neutro masculino por lax cuando a personas se refiera, ya que considero que es una práctica que permite señalar $y$, en cierta medida, desarticular el androcentrismo consolidado en el lenguaje.
4 Este fragmento pertenece al texto que acompaña la entrada al blog donde se presenta la obra Una nueva artista necesita usar el baño. colectivamente entre amigxs o compañerxs ${ }^{3}$ de cursada o de forma individual, dibujó comics basándose en sus experiencias cotidianas y posó en muestras para que la dibujaran. Realizó intervenciones en espacios públicos como la calle o el UNA, también en la intimidad de su casa. Algunos de los temas que trabajó fueron la identidad, la sexualidad, el género y el cuerpo. Aunque varíen con relación al formato, al espacio donde se realizan y a la disciplina, las obras coinciden en la construcción de un registro meticulosamente organizado que la artista publicó en una serie de blogs iniciados en 2009. Además de contar con los registros fotográficos de las obras, estos blogs contienen textos de su misma autoría que acompañan, a modo de profundización poética y conceptual, las obras. En estos textos hacía referencia a Ixs artistas que citó, a los temas que trabajó o a los aspectos que fueron de mayor interés para realizar su producción. Los blogs y los textos son un aspecto característico de la producción de Effy y proporcionan un modo de acceder a sus registros y de ver la forma en que la artista veía su obra. De este modo, podemos conocer, a través de una fuente directa, en qué clave han sido formuladas sus producciones.

Por mecánica propia de los servidores donde se alojan estos archivos que componen los blogs, al pasar los años, han ido desapareciendo las imágenes que habían sido publicadas. Por esta razón, Que el mundo tiemble, cuerpo y performance en la obra de Effy Beth (2016), de Matías Máximo, recupera el material que se había perdido en los blogs. Este libro - que fue proyectado por Effy y que se construyó con acceso a su computadora personal- es una de las fuentes fundamentales de esta investigación, en él se encuentran las obras de forma similar a como se encontraban en las páginas en las que se habían publicado originalmente.

En este trabajo nos interesa analizar dos de sus obras performáticas: Una nueva artista necesita usar el baño (2010) y Nunca Serás Mujer (2011).

\section{"Siendo yo mujer trans y artista conceptual»"}

Una nueva artista necesita usar el baño consiste en una fotoperformance realizada en 2010, el mismo año en que Effy comenzó la carrera de Artes Visuales en la UNA. Nuestro acercamiento es posible a partir de un registro fotográfico de la obra y de un texto escrito por Effy, ambos publicados en uno de sus blogs. 


\section{effýmia}

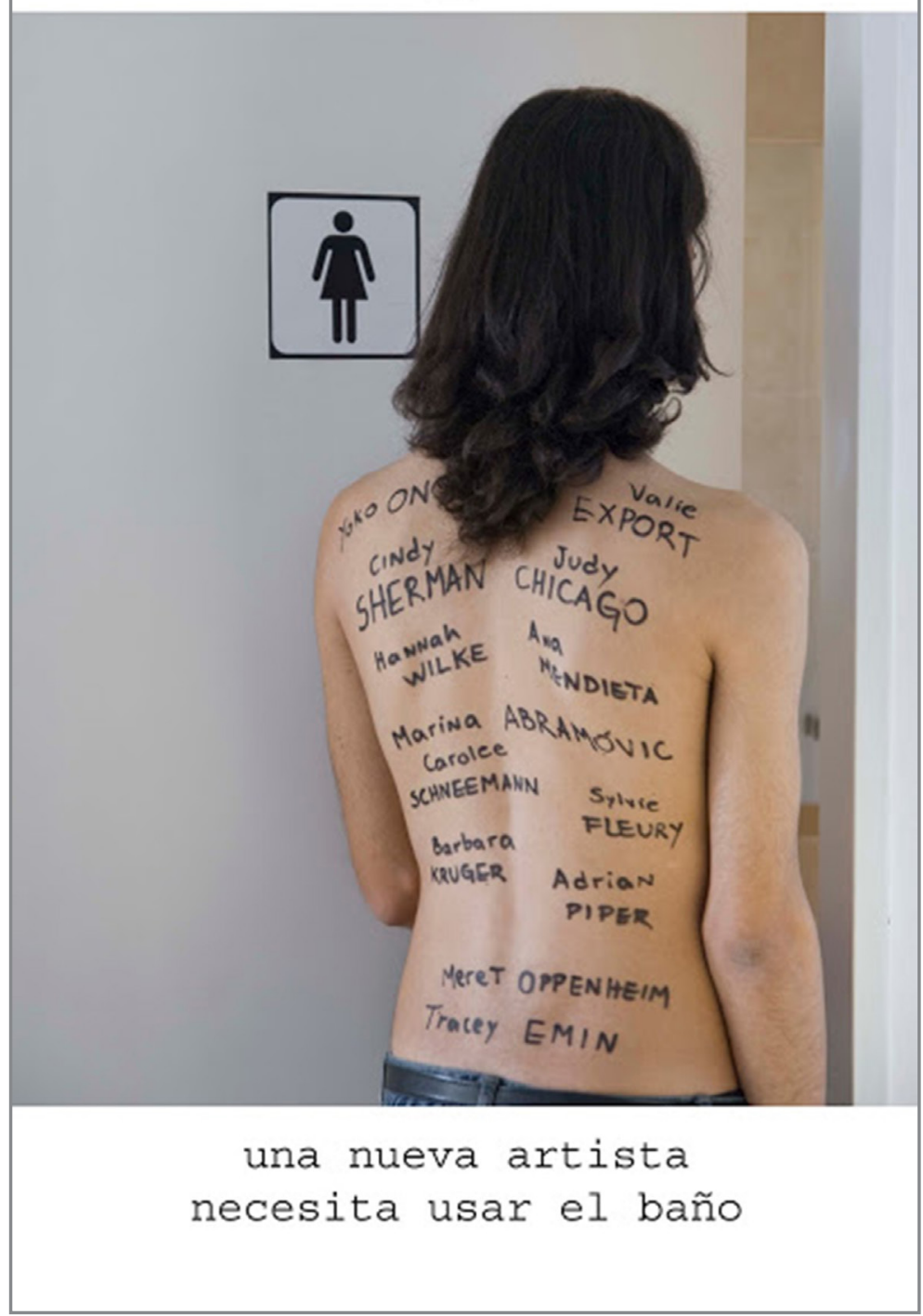

Figura 1. Registro de la acción subido al blog

En la fotografía vemos a Effy entrando a un baño. La puerta lleva la característica señalética con la que son identificados los baños de mujeres. Effy tiene el torso desnudo y en su espalda lleva escrito en listas a ambos lados de su columna vertebral los nombres de varias artistas: Yoko Ono, Valie Export, Cindy 
Sherman, Judy Chicago, Hannah Walkie, Ana Mendieta, Marina Abramovic, Carolee Schneemann, Sylvie Fleury, Barbara Kruger, Adrian Piper, Meret Oppenheim y Tracey Emin. En el texto que acompaña la fotografía en la entrada del blog encontramos varios puntos relevantes, Effy explica:

[...] he pensado en una manera de hacer una presentación digna de mi persona que me reafirme en estos aspectos de mi identidad. Las mujeres transexuales aún estamos invisibilizadas como mujeres ante la cultura donde aún rige el pensamiento machista y falocéntrico (Effy en Máximo, 2016, p. 248).

En tal sentido, la obra funciona como una presentación y, a su vez, traza el objetivo de problematizar la invisibilización de las mujeres trans. Aquí se trazan relaciones con la genealogía de artistas que Effy construye, otorgándoles el lugar de antecesoras a las que inscribe en su cuerpo y a ella misma como la artista nueva que continúa con el legado.

\footnotetext{
En la espalda tengo escrito los nombres de varias artistas mujeres que lograron transgredir en el arte desde su género [...] Al igual que varias producciones de las mujeres artistas citadas en mi cuerpo, la propia hace honor a mis predecesoras, y es una invitación a realizar cambios de paradigmas en ésta y futuras generaciones (Effy en Máximo, 2016, p. 248).
}

Podemos reconocer una serie de estrategias poéticas y discursivas como la inscripción de los nombres a ambos lados de su columna, que se encuentran guardando y cubriendo su cuerpo y llevar el torso desnudo mientras entra al baño tradicionalmente señalizado como baño de mujeres. De estas estrategias destacaremos la explicación del uso de esos nombres en el texto que acompaña la publicación en el blog, ya que así Effy se enuncia como miembro de esta genealogía. Ingresa del mismo modo en el que su cuerpo entra al baño, declarando ese espacio y esa historia como propia. Las artistas que componen la genealogía que nombra son mujeres cis, europeas y estadounidenses -esto incluye casos como los de Yoko Ono y Ana Mendieta, que luego de migrar de sus países de origen obtuvieron la ciudadanía estadounidense- . Así mismo, son artistas conceptuales y performáticas que, en términos generales, han operado críticamente sobre los discursos dominantes con relación al papel asignado socialmente a la mujer, recurriendo en algunos casos a un «modo de expresividad diferente de las mujeres y del "ser mujer» (o de una «identidad sexual femenina»)» (Gutiérrez, 2015, p. 5). Unos de los tropos estéticos frecuentemente utilizado por estas artistas es el uso de la 
5 Resulta llamativo que la lista confeccionada por Effy omite los nombres de artistas ajenas a las narrativas canónicas del arte europeo y estadounidense. Aunque no es una problemática a desarrollar en este trabajo, es inevitable instalar esta pregunta al referirnos a una acción que, a la vez que cuestiona el cisexismo de la historia del arte (y de la historia del arte feminista), al mismo tiempo, parece pasar por alto el orden colonial que regula esas narrativas.

6 Parte de la breve descripción personal "artista conceptual, performática y feminista queer» presente en uno de sus blogs.
7 Con esta frase concluye la obra Nunca Serás Mujer en su decimotercera acción. «iconografía vaginal» (Gutiérrez, 2008), que incluye el uso de la menstruación como material artístico.

Si bien estas artistas y estos recursos han problematizado, señalado y avanzado sobre el androcentrismo dentro del campo artístico, han recurrido a estrategias estéticas cisexistas, ya que apelan a una presunta verdad del sexo como matriz de diferenciación necesaria y obligatoria de los géneros, corriendo el riesgo de esencializar la identidad femenina. Además, los relatos que se construyen desde y alrededor de estas prácticas artísticas no solo insisten en estos tropos, sino que también han guardado un profundo silencio respecto a las subjetividades y experiencias trans y travestis. $^{5}$

Entrar al baño, como explica Effy, «sin usar falda, ni sostén, solo con el pelo un poco largo y en cuero (tal como lo podría estar un hombre según los códigos de vestimenta que conocemos)" (Effy en Máximo, 2016, p. 248) nos permite distinguir que su ingreso a la genealogía que traza, luego de reconocer una herencia compartida con las artistas que nombra, es un ingreso diferencial, incómodo o queer. 0 , más precisamente, «feminista queen», ${ }^{6}$ forma en la que la artista se autodenominó. Aquí el término queer señala una operación crítica hacia dentro de los movimientos feministas que, como Lorenzo Bernini (2018) advierte, «también producen en su seno modelos normativos, mecanismos de exclusión y órdenes jerárquicos» (p. 99), cuya institucionalización "amenaza a realizarse a expensas de otras subjetividades minoritarias» (p. 99).

La operación que Effy realiza no es solo una crítica o la adición a la genealogía, sino que es, también, un aprovechamiento del canon estable que se construyó alrededor de estas obras y artistas, ella se apropia y hace uso de esa característica, pero tensiona a su vez los mismos aspectos que la vuelven estable. Se trata de la construcción de una genealogía crítica que tuerce y descentra los alcances de las narrativas institucionalizadas en sus proyecciones de sentido, al señalar las mecánicas de poder cisnormadas que las ordenan y regulan.

\section{"Siempre soy mujer»"}

Nunca Serás Mujer es una obra compuesta de trece acciones que se realizaron en distintos espacios de la ciudad de Buenos Aires durante 2011. Como ella relata, la obra parte de una frase que una persona dirigió a Effy con relación a su tratamiento de reasignación hormonal: "Aunque vos te sientas mujer, te crezcan las tetas, tomes hormonas, te operes los genitales, nunca serás mujer porque no menstruás ni sabés lo que eso significa» (Effy en Máximo, 2016, p. 78). Al cumplirse un año del inicio de su trata- 
miento, la artista explica: «Extraigo de mi cuerpo toda la sangre que debería haber menstruado desde entonces, es decir, la misma cantidad de sangre que pierde por año la mujer que menstrúa (medio litro aproximadamente)» (Effy en Máximo, 2016, p. 78). Luego repartió la sangre en trece partes, representando una menstruación por cada mes que pasó desde que inició su tratamiento y con cada una de ellas realizó una acción durante abril de ese año. La secuencia en la que la artista ordena las acciones está relacionada con lo que vivió cada mes respecto a la construcción de su identidad de género (Effy en Máximo, 2016), y no se corresponde con la sucesión temporal del calendario. Por esta razón, el orden de las acciones no coincide con el de las fechas.

En la acción que inicia la obra, llamada "Primera menstruación", la artista vistió ropa interior masculina, un boxer que manchó en la entrepierna con la primera dosis de menstruación. La segunda acción, «Mi menstruación de mayo», fue el 12 de abril de 2011 en un aula de la UNA, con el apoyo del Departamento de Artes Visuales y el auspicio del Instituto Nacional Contra la Discriminación, la Xenofobia y el Racismo (INADI). Effy se extrajo sangre en público y luego se disfrazó de hombre: «Me disfrazo de hombre, tal como me vestía aquel mes» (Effy en Máximo, 2016, p. 80), es decir, cuando comenzó la carrera en 2010. Introdujo su mano por debajo del pantalón, la sacó manchada de sangre y la enseñó al público. Por último, alzó su mano y dijo: «Mi nombre es Elizabeth Mía Chorubczyk. Presente» (Effy en Máximo, 2016, p. 81).

En «Mi menstruación de junio», tercera acción, realizada el 19 de abril de 2011, la artista entró a la Iglesia de la Piedad sosteniendo una copa cargada con su menstruación, se arrodilló y pidió perdón a las personas que trataron de amarla y resultaron heridas (Effy en Máximo, 2016, p. 82). Finalizó la acción bebiendo su menstruación. En la cuarta, «Mi menstruación de julio», el 30 de abril de 2011, la artista intervino el espacio público del microcentro porteño con tampones manchados de sangre, algunos fueron colgados en los mismos lugares en donde había volantes de trabajadoras sexuales pegados. La quinta acción, "Mi menstruación de agosto», se realizó el 30 de abril de 2011 en una sucursal de la prepaga de salud OSDE. Con una mano llena de sangre de menstruación manchó el logotipo que se encontraba en la fachada de la sucursal.

«Mi menstruación de septiembre», sexta acción, la realizó el 27 de abril de 2011 en la intimidad de su hogar. Untó su cara con una parte de su menstruación como mascarilla de belleza y la otra la mezcló con cera que luego usó para depilarse las axilas. La séptima fue "Mi menstruación de octubre" y la hizo el 27 de abril de 2011 en su casa. Al respecto Effy explica: «Vuelvo a disfrazarme de hombre tal como lo hacía para el trabajo» (Effy en Máximo, 2016, 
p. 89). Luego baña sus uñas en su menstruación y se rasguña los brazos hasta detenerse por el dolor.

"Mi menstruación de noviembre», octava acción, se realizó el 19 de abril de 2011 en dos partes. La primera tuvo lugar en los alrededores de la UNA y la segunda dentro de un baño de la misma institución. En esta acción, Effy llevó puesto un vestido blanco que manchó con menstruación, caminó por las calles alrededor de su facultad como si «estuviese en una pasarela de moda» (Effy en Máximo, 2016, p. 93), los hombres le silbaban y le gritaban piroposignorando la sangre. Luego, entró al baño donde se quitó el vestido y lo lavó con agua intentando sacar las manchas de sangre. «Mi menstruación de diciembre» fue la novena y consistió en una fotoperformance realizada el 19 de abril de 2011. Effy tachó el nombre que aparecía en su DNI y escribió «Elizabeth Mía» en su brazo, lo extendió sosteniendo el DNI en su mano, como entregándolo. «Mi menstruación de enero» fue el 19 de abril de 2011 frente al Congreso de la Nación. Effy creó un círculo con su menstruación en la vía pública y se sentó sola dentro de este.

La undécima acción, «Mi menstruación de febrero» fue una intervención urbana en la Estación Florida de la línea B de Subte, realizada el 28 de abril de 2011. Aquí la artista dejó un rastro de sangre en las escaleras simulando un «llamado de apareamiento» (Effy en Máximo, 2016, p. 98). «Mi menstruación de marzo» consistió en una pintura-performance realizada en su casa el 27 de abril de 2011. Effy se mojó el cabello con su menstruación para luego utilizarlo como pincel con el que realizó una pintura sobre papel, mientras declaraba: «Mi mente es mi aparato reproductor femenino: fértil y capaz de reproducir ideas para que formen parte de la siguiente generación» (Effy en Máximo, 2016, p. 99). En su «Última menstruación», realizada a solas en la intimidad de su hogar el 27 de abril de 2011, Effy escribió con su menstruación «siempre soy mujer" sobre un espejo donde podía verse el cuerpo entero, luego subrayó la palabra mujer con su pene.

A diferencia de Una nueva artista necesita usar el baño, en Nunca Serás Mujer no aparecen citas o referencias explícitas a la genealogía de artistas que construyó. No obstante, el uso de su sangre como representación de menstruación remite a las iconografías vaginales trabajadas principalmente en los setenta por artistas que componen su genealogía. Esta vez, el recurso de la menstruación está tensionado, se encuentra separado del esencialismo que afirma una identidad sexual femenina y está puesto a señalar los espacios y las situaciones que construyen y disciplinan cuerpos y subjetividades generizadas: una prepaga de salud que se niega a cubrir su tratamiento hormonal, la piel sin depilar, la calle donde la circulación del cuerpo generizado aparece regulada y controlado por distintos órdenes de poder, un baño público. 
Leer este grupo de acciones, es decir, la obra Nunca Serás Mujer en relación con la genealogía trazada por Effy, descentra las narrativas que se han consolidado alrededor de las prácticas de esas artistas, es decir, complejizan la mirada y las lecturas de la historia del arte. Más que una mera incorporación de otra artista y de su obra, se trata de reconocer un legado compartido, pero no estático o estanco, sino en disputa, para volver sobre sus propias prácticas, para seguir profundizando sus debates o para tensionarlos. Nos permite advertir los órdenes de poder entramados en la historia del arte y, de este modo, habilitar interpelaciones críticas a sus epistemologías normalizadas.

\section{Conclusiones}

En su obra, Effy interpela de forma poética y crítica las narrativas artísticas feministas. A través de estrategias de cita y de retomar imágenes y procedimientos que han sido tropos estéticos recurrentes en una serie de artistas, trazó una genealogía con la que reconoció un legado compartido, construyó una historia que le habilitó formular el objetivo de visibilizar y problematizar cuestiones de género. También, trazó identificaciones en las que consideró a las artistas que componen dicho legado como sus antecesoras y a ella como la nueva artista que se propone seguir generando cambios de paradigma.

Su ingreso a esta genealogía compuesta de artistas mujeres cis, europeas y estadounidenses, de renombre, pertenecientes a las corrientes conceptuales y performáticas en la historia del arte, es un ingreso que descentra o interrumpe la estabilidad de dichas narrativas. Utiliza su sangre como representación de su menstruación, pero está desviada de un esencialismo que la ligue a una verdad del sexo como matriz inapelable del género, más bien, señala esos espacios y situaciones que vigilan y construyen cuerpos, géneros e identidades.

La razón por la que leemos sus obras con relación a la genealogía construida es que nos permite advertir el cisexismo que ordena y que administra los relatos de la historia del arte $y$, hasta cierto punto, permite desmontar las lógicas de poder que producen y que disciplinan nuestros cuerpos y subjetividades. 


\section{Referencias}

Aumont, J. (1992). La imagen. Barcelona, España: Paidós.

Bernini, L. (2018). Las teorías queer. Una introducción. Barcelona, España: Egales.

Chorubczyk, E. (2011). Nunca Serás Mujer [Performance]. Recuperado de http://nuncaserasmujer.blogspot.com

Chorubczyk, E. (27 de septiembre de 2010). Una nueva artista necesita usar el baño [Entrada de blog]. Recuperado de http://tengoefymia.blogspot.com/2010/09/una-nueva-artista-necesita-usar el-bano.html

Gutierrez, M. L. (2008). Crítica a la estética androcéntrica. Arte y feminismo en la cultura contemporánea (Tesis de Licenciatura). Facultad de Ciencias de la Educación de la Universidad Nacional de Entre Ríos, Argentina.

Gutiérrez, M. L. (2015). Entre las intervenciones feministas y el arte de mujeres. Aportes, rupturas y derivas contemporáneas de los cruces entre arte y feminismos. Asparkia, (27), 65-78. Recuperado de http://www.e-revistes.uji.es/index.php/asparkia/article/view/1481/1737

Máximo, M. (2016). Que el mundo tiemble. Cuerpo y performance en la obra de Effy Beth. La Plata, Argentina: Edulp. 